\title{
Moving and handling of patients with dementia
}

\author{
Dev Jootun', Aileen Pryde ${ }^{2}$ \\ 1. Hamilton Campus, University of the West of Scotland, Caird Building, Hamilton, Lanarkshire, UK. 2. Victoria Hospital, \\ Kirkcaldy, Fife, UK.
}

Correspondence: Dev J ootun. Address: Hamilton Campus, University of the West of Scotland, Caird Building, Hamilton, Lanarkshire, Uk. ML3 0QA. Telephone: 01-698-283-100 Ex. 8647. Email: dev.jootun@uws.ac.uk.

Received: May 30, 2012

DOI : $10.5430 /$ jnep.v3n2p126
Accepted: June 21, $2012 \quad$ Published: February 1, 2013

URL: http://dx.doi.org/10.5430/jnep.v3n2p126

\section{Abstract}

Moving and handling is an important aspect of caring for patients with dementia. This can be a serious risk to health care staff, and requires careful risk assessment and planning before execution to minimise any injury. This article explores some of the challenges nurses may face when moving and handling people with dementia. It offers guidance on how to deal with these challenges to promote safe practice and improve patient outcomes.

\section{Key words}

Moving and handling, Dementia and mobility

\section{I ntroduction}

Moving and handling of patients is an integral part of nursing, however, there is a high incidence of back injury in nursing staff while manually handling patients ${ }^{[1,2]}$. This level of injury and the implementation of health and safety legislation in $1992{ }^{[3]}$ have led to changes in the way nurses are prepared for moving and handling. This training became a statutory requirement that educational establishments must provide for students. This strand runs through the nursing curriculum and the teaching is adapted to suit the subsequent practice placements for students. Regular updating of students throughout the course is seen as a good way of helping them become safe practitioners.

The RCN's Code of practice for Handling Patients ${ }^{[1]}$ advocates that new nurses are given a sound theoretical base for safe handling and moving followed by adequate practice prior to starting practice. In 1994, the University of the West of Scotland's School of Health Studies introduced a new approach to teaching moving and handling based on the neuromuscular approach (NMA) to efficient moving and handling. This approach is primarily concerned with teaching students to move efficiently, which means performing the required task in a way that produces the least possible fatigue and strain, consequently minimising injury ${ }^{[4]}$.This approach was also informed by the principles in the Manual Handling Operations Regulations ${ }^{[3]}$ as amended in 2002. The aim is to educate student nurses to use sound principles and a problem solving approach to determine safe solutions to patient moving and handling challenges.

For practice placements, students are placed mainly in care homes and care of the Elderly wards where many clients/patients have dementia. Alzheimer's Society ${ }^{[5]}$ states that $64 \%$ of people living in care homes have a form of dementia. The number of people with dementia is steadily increasing and the Alzheimer's Society believes that careful and 
appropriate planning and training are needed to ensure that the right care and support is available to allow people with dementia to maintain the best possible quality of life for as long as possible.

\section{Moving and handling of patients with dementia}

The term "dementia" is used to describe signs and symptoms that occur when the brain is affected by specific diseases and conditions. The Mental Health Foundation ${ }^{[6]}$ defines dementia as a decline in mental ability which affects memory, thinking, problem solving, concentration and perception. Walsh ${ }^{[7]}$ states that dementia is a term used to describe a group of brain disorders which have a profound effect upon the individual's life. Whatever its form, it will usually impact upon memory and orientation to time, place and person. The gradual decrease in cognitive ability means that the ability to think and communicate gradually decline and the persons finds it difficult to learn new information and express their needs. Dementia is progressive, with the symptoms gradually getting worse and will affect each person in a unique way.

Cognitive impairment in dementia limits the ability of the person to communicate effectively which could impinge on the nurse's ability to clearly identify their needs, and potentially affect the nursing interventions. It is vital that the nurse when caring for people with dementia is able to use good communication skills to engage in a therapeutic way to be able to identify the ability or disability of the person. Jootun and McGhee ${ }^{[8]}$ argue that communication is at the heart of all approaches to dementia care and they examine some of the challenges nurses may face when caring for people with dementia and suggest some strategies which can be used to overcome the barriers and enhance the quality of care. They provide practical tips on how the nurse can connect and engage in a meaningful way with the person with dementia by adapting the communication process. Because of the challenging behaviour and uncertainty of how to communicate with a person with dementia, the nurse may be unable to identify the holistic needs which compromises the quality of care that person received. Dementia leads to progressive decline in multiple areas of the brain and the ability to mobilize and carry out daily activities ${ }^{[9]}$. Maintaining mobility and independence is a vital part of caring for people with dementia.

\section{Promoting mobility in patients with dementia}

Promoting mobility in people with dementia has a physiological, psychological and social benefits ranging from healthy bones to maintaining their independence. Burns et al. ${ }^{[10]}$ found that regular exercise slows down the decline of cognitive ability and reduces brain atrophy. The nurse needs to appreciate the importance of maintaining mobility for as long as possible through safe interventions. The safe moving and handling of patient with dementia is not without risk, but there appears to be a paucity of literature and guidance on the topic. It is vital for the nurse to understand the effect of dementia on the individual. Dementia can have a major impact on the individual's ability to make sense of the environment. With increasing cognitive impairment people with dementia can experience a slowing down of responses and actions ${ }^{\text {[11] }}$. McKeefry and Barlett ${ }^{[12]}$ in their study found that people with dementia can have reduced visual acuity, contrast sensitivity and colour vision, as well as spatial awareness and depth perception. The ability of a person to cope with gradual visual impairment can influence their cognitive performance, mobility and daily living activities.

Patients are affected in different ways with dementia and there are many different illnesses which cause dementia ${ }^{[13]}$. Too often patients are grouped together, just because they have a diagnosis of dementia leading to a universal rather than an individualized approach to how they are managed. It is important to see the patient as an individual with unique needs before holistic, patient-centred care can be provided. Comprehensive and systematic assessment is key, prior to any intervention. A thorough process should be used for data collection to build a good picture of the ability or disability of the patient. This should include:

- Ability of the patient to walk unaided.

- $\quad$ Aids the patient uses when walking. 
- Level of assistance required.

- Any required equipment to perform the task safely.

Edge ${ }^{[14]}$ recommends doing an ability test as part of the assessment process. This test informs the nurse of the patient's understanding of the instructions, cooperation and coordination. It helps you to assess the strength and mobility in the patient's limbs and trunk. The Time Up and GO (TUG) test designed by Podsiadlo and Richardson ${ }^{[15]}$ is another simple way of measuring the physical mobility of the patient. TUG is a useful outcome measure that physiotherapists use especially in relation to tracking progress of rehabilitation and predicting further falls. It can be a difficult tool to use with patients with dementia because the description is given and then prompts shouldn't be made. It therefore relies strongly on understanding a sequence of instructions and remembering them in order to complete the task. The nurse completing the task would have to understand if the patient didn't complete this TUG; is possibly because of a cognitive or a physical problem or a combination of both. For this reason physiotherapists have a repertoire of tools including, Timed sit-to-stands, Timed unsupported steady stand (TUSS), TUG, Elderly mobility scale, $6 \mathrm{~m}$ walk, $10 \mathrm{~m}$ walk, 180 degree turn test and many strength and range of movement tests. The authors suggest that you should choose the measure most appropriate to the patient, utilising as much patient history as you can, therefore maximizing the chances of success that the patient will achieve the task with the minimum physical effort for all.

Once the assessment is completed and the mobility needs of the patient have been identified, the nurse should refer to Box 1 and Box 2 for safe performance of the task. People with dementia can communicate in many different ways and not all of them require speech. In some patients non-verbal, such as the use of touch and body language are more important when interacting with the person with dementia to connect in a meaningful way to facilitate the manoeuvre ${ }^{[8]}$. The MHOR ${ }^{[3]}$ as amended in 2002 provides useful practical advice for safe moving and handling and how to reduce the risk of injury from moving and handling tasks. These include:

- Use the information provided by the patient, their carers and other professionals to ensure that you, as a nurse, are clear in your expectations about how much you will need to do, what equipment you'll need and how much assistance the patient will need.

- Explain to the patient the task and its purpose.

- Ask the patient to do as much as they can themselves

- Be patient.

- Repeat the explanation as frequently as seems required.

- Place the appropriate walking aid in position and ensure that the patient knows that it is there.

- Don slippers/shoes or ensure that they are fitting correctly.

- Move furniture which is encroaching the space i.e. hospital tables on wheels.

Doing this demonstrates clearly what the task is, what is expected of the patient and how you are going to assist. It allows the patient time to process their thoughts so that they can participate. It is less likely to be distressing to the patient and therefore simpler for all concerned.

- Good moving and handling technique involves thinking before lifting or moving. Plan what you want to achieve with the patient and how you are going to achieve it.

- Prior to starting the manoeuvre adopt a stable position and get a good hold of the patient as close to you as you can.

- Start moving and handling the patient with a good posture. Make sure you bend your back, hips and knees slightly. Do not stoop or fully flex the hips and knees (squatting). 
- Don’t flex the back any further while performing the manoeuvre.

- Avoid twisting your back or leaning sideways.

- Keep your head up and move smoothly.

- Don’t move and handle more than you can manage.

- Avoid lifting the patient as far as it’s practical and use appropriate lifting equipment.

The patient needs to be able to bear their own weight for manual moving and handling. Where patient is not able to weight-bear, the only safe option is to use appropriate equipment.

Dementia can affect mobility in different ways and the degree of cognitive impairment varies from individual to individual. This can lead to a wide range of problems that make it difficult for the patient to judge their position in relation to their environment. Sander ${ }^{[16]}$ states that it is common for the patient with dementia to have visuo-spatial disorientation. This means that close objects may seem further away and distant objects closer than they really are. The patient may try to sit down when the chair is still a good distance way. This can be prevented by walking the patient close to the chair to have a good look at the chair, then turn the patient round and give simple and clear instructions to put their hands on the arms of the chair and allowing the back of their legs to touch the chair before sitting down. Positive statements are normally more effective such as “keep standing” or "stay standing up tall” rather than “don’t sit down”. Emphasize what you wish them to do.

Patients with dementia may be afraid of moving for fear of falling and many are not able to put their fear into words, but show it by their behavior. If they are sitting in a chair and are asked to move, they may push themselves back into the chair and grip the arms of the chair tightly. If the patient is grasping the arms of the chair prior to standing up, do not release the grip by lifting the hands, this further tighten the grasp. Grealy et al ${ }^{[17]}$ recommend that you lightly stroke the back of the hand; this relaxes the grasp by stimulating the extensor muscles of the hand. Once the patient releases the grip, use the appropriate taught technique to provide support for standing and walking away from the chair. Alzheimer's Society ${ }^{[18]}$ and Oddy ${ }^{[19]}$ provide useful tips that can be used when moving and handling patients with dementia by one nurse or two nurses.

Changes to the environment when moving to a care home or a hospital ward can reduce the patient's willingness to mobilize. The decreasing ability to make sense of their surroundings and tendency to misinterpret visual cues and sound can lead to the patient be coming confused and frightened. It is important for the nurse to understand the reasons for this type of behavior. By adapting the environment, the nurse can help the patient to move with more confidence. Grealy et al. provide some tips on how the environment can be adapted to make the patient feel safer ${ }^{[17]}$. Reducing the noise level, better lighting and minimizing patterns on the floor can make the patient feel safer. Contrasting colours for wall and objects in the room will make it easier for the patient to recognize them. This can seem impossible to do, especially in a hospital setting. However, having you and your patient enclosed behind the curtain within the ward can have a significant effect either positively or negatively. A single room maybe vital for some patients but totally inappropriate for others.

\section{Reducing risks in moving and handling people with dementia}

This section provides practical advice on how to perform safe moving and handling when working with dementia patients. It is vital to carry out a risk assessment prior to moving and handling a person with dementia. The HSE guidance on regulations for manual handling ${ }^{[3]}$ advocates nurses use this simple hierarchy of measures prior to performing any moving and handling task (see Table 1). 
Table 1. Hierarchy of measures

\begin{tabular}{|l|l|}
\hline AVOID & $\begin{array}{l}\text { Avoid the need for a moving and handling operation which involves a risk as far as reasonably } \\
\text { practicable. Is there another way the task can be performed which avoids the need to lift? }\end{array}$ \\
\hline REDUCE & $\begin{array}{l}\text { If the Moving and Handling operation cannot be avoided, you need to make a "suitable and } \\
\text { sufficient" assessment of the risk involved. }\end{array}$ \\
\hline REVIEW & $\begin{array}{l}\text { Through assessment the risk of injury is reduced to the lowest possible level that is reasonably } \\
\text { practicable. You need to implement the appropriate measures to reduce the risk. Employees are } \\
\text { required to make use of appropriate equipment provided to them in accordance with the training } \\
\text { and instruction provided by their employer and follow safe systems of work laid down by their } \\
\text { employer to promote safety during handling any load. }\end{array}$ \\
\hline
\end{tabular}

Table 2. Practical advice on what to look for when making risk assessments of moving and handling activities

\begin{tabular}{|c|c|}
\hline Task & $\begin{array}{l}\text { When assessing the task you need to think of: } \\
\text { What do you have to do and do you have to do it. } \\
\text { What actions are required to carry out this task? } \\
\text { Twisting. } \\
\text { Stooping } \\
\text { Stretching } \\
\text { Holding load away from the trunk. } \\
\text { Unpredictable movement. } \\
\text { Will this task require frequent or prolonged physical effort? } \\
\text { What is the distance you need to move the patient? }\end{array}$ \\
\hline $\begin{array}{l}\text { Individual capability } \\
\text { and } \\
\text { Competence }\end{array}$ & $\begin{array}{l}\text { This relates to the handler capabilities and competence. } \\
\text { Will this require unusual strength or height? } \\
\text { Does it require special knowledge or training? } \\
\text { Do you need to perform the task? } \\
\text { Is there any factor that affecting your performance? } \\
\text { Also think about own clothing, jewellery etc. } \\
\text { Some other points to remember include } \\
\text { Explanation to the patient, gaining consent to ensure their co-operation and participation. } \\
\text { Establishing the teams' limitations, experience and knowledge of the approach. } \\
\text { Ensuring that everybody who is involved is clear of what you want to achieve with the patient. } \\
\text { Ability to use equipment safely. }\end{array}$ \\
\hline Load & $\begin{array}{l}\text { This refers to the patient who needs to be moved. } \\
\text { Can the patient cooperate? } \\
\text { Does the patient have any physical or behavioural constraints, an understanding of what is happening, } \\
\text { are they in pain? } \\
\text { Is the patient behaviour unpredictable? } \\
\text { Is the patient attached to any equipment or tube? } \\
\text { Some additional points to consider } \\
\text { Weight is only one factor to be considered. } \\
\text { Patient's diagnosis/ stage of progression of dementia. } \\
\text { Does the patient have any ability to assist } \\
\text { Can the patient move without assistance. } \\
\text { How much help does the patient need. }\end{array}$ \\
\hline Environment & $\begin{array}{l}\text { When assessing the environment you may need to consider the following: } \\
\text { Any space constraints, preventing good posture? } \\
\text { Uneven, slippery, unstable floors? } \\
\text { Variations in levels of floor or work surfaces? } \\
\text { Poor lighting conditions? } \\
\text { Extremes of temperature or humidity? } \\
\text { Remember brakes, position and height of equipment you need to use. }\end{array}$ \\
\hline
\end{tabular}

For all unavoidable manual handling operations that involve a risk of injury to employees a suitable and sufficient assessment of these operations need to be made. Table 2 contains practical advice on what to look for when making risk 
assessments of moving and handling activities. It breaks these down according to various task factors, capability and competence of the individual performing the task, aspects of the loads and the working environment (TILE). It is also important for the nurse to be aware, at all times, the relevant policies and protocols that are in place for safe and effective practice.

A short Guide to safe Practice is available from the HSE @ this site: http://www.hse.gov.uk/pubns/indg143.pdf

Dementia is a progressive disease leading to more marked disability and the ability of the person will decrease. The assessment of the patient needs to be updated and the level of intervention and support offered will need to be adjusted to suit the needs of the patient. If the patient's behaviours become unpredictable or is unable to weight-bear, the nurse must choose the safest option and use appropriate equipment. Nurses caring for patients with dementia need to appreciate the importance of maintaining mobility for as long as possible. It helps the patient to maintain some control, independence and has many other benefits. However, moving and handling of this patient group is high risk and the nurse need to be able to adapt the taught principles and use some of the suggested strategies in this article for safe and effective interventions.

\section{References}

[1] Royal college of Nursing. Code of Practice for Handling Patients. RCN, London. 2002.

[2] Health and Safety Executive. Health and Safety Executive Statistics 2007/2008. Sudbury, Uk. 2008.

[3] Health and Safety Executive. Manual Handling. Guidance to the Regulations. HMSO, London. 1992.

[4] Crozier L, Cozens. The Neuromuscular Approach to Human Movement: A Course for movement Facilitators. Course Handbook. MoVES, Edinburgh. 2002

[5] Alzheimer's Society. Leading the fight against Dementia [Internet]. 2011. Available from: http://alzheimers.org.uk/site/scripts/documents_info.php?documentID=341 (Last accessed: January 25th 2012.)

[6] Mental Health Foundation [Internet]. Dementia. 2006. Available from: http://www.mentalhealth.org.uk/information/mental-health-a-z/dementia/ (Last accessed: January 25 2012.)

[7] Walsh D. Dementia care training manual for staff working in Nursing and residential setting. Jessica Kingsley Publishers, London. 2006.

[8] Jootun D and MCGhee G. Effective Communication with People who have Dementia. Nursing Standard. $2011 ; 25$ (25): $40-46$.

[9] Department of Health. Living Well with Dementia. A National Dementia Strategy. The Stationary Office, London. 2009.

[10] Burns M J, M.D.; Cronk B B, Anderson H S, et al. "Cardiorespiratory Fitness and Brain Atrophy in Early Alzheimer's Disease." Neurology. 2008; 71: 210-216.

[11] Killick J, Allan K. Communication and the Care of People with Dementia. Open University Press, Buckingham. 2001.

[12] McKeefry D and Bartlett R. Improving Vision and Eye Health Care to people with Dementia. Pocklington Trust, Bradford. 2010.

[13] Goldsmith M. Hearing the voices of people with dementia: Opportunities and Obstacles. JKP, London. 2002.

[14] EDGE Services. People Handling and Risk Assessment. EDGE, York. 2010.

[15] Podsiadlo D and Richardson S. The Time "up and Go": a test of basic functional mobility for frail elderly persons. Journal of the American Geriatric Society. 1991; 39(2): 142-148. PMid:1991946

[16] Sander R. Standing and Moving: helping people with vascular dementia. Nursing Standard. 2000; 14(1): $20-25$.

[17] Grealy J, McMullen H and Grealy J. Dementia Care: a practical photographic guide. Blackwell Publishing, Oxford. 2005.

[18] Alzheimer's Society. Moving and Handling: Advice sheet [Internet]. 2000. Available from: http://www.dementie.be/SiteFiles/513_Moving_and_Handling.pdf (Last accessed: February 6th 2012)

[19] Oddy R. Promoting Mobility for people with Dementia; A problem solving approach. Age Concern, London. 2003. 